\title{
Downregulation of fungal cytochrome $c$ peroxidase expression by antifungal quinonemethide triterpenoids
}

\author{
Woo-Duck Seo ${ }^{1} \cdot$ Dong-Yeol Lee ${ }^{2} \cdot$ Ki Hun Park ${ }^{2} \cdot$ Jin-Hyo Kim² ${ }^{2}$
}

Received: 23 May 2016 / Accepted: 29 June 2016 / Published Online: 31 December 2016

(C) The Korean Society for Applied Biological Chemistry 2016

\begin{abstract}
To handle the development of antifungal drug resistance, the development of new structural modules and new modes of action for antifungals have been highlighted recently. Here, the antifungal activity of quinonemethidal triterpenoids such as celastrol, dihydrocelastrol, iguestein, pristimerin, and tingenone isolated from Tripterygium regelii were identified (MIC 0.269$19.02 \mu \mathrm{M})$. C. glabrata was the most susceptible to quinonemethide among the tested fungi. Furthermore, quinonemethide suppressed cyctochrome $c$ peroxidase expression dramatically, decreasing fungal viability caused by the accumulation of hydrogen peroxide. Thus, cyctochrome $c$ peroxidase downregulation of quinonemethide may be a key mode of action for antifungals.
\end{abstract}

Keywords Anti-fungal $\cdot$ Antioxidant $\cdot$ Cytochrome c peroxidase - Quinonemethide triterpenoid

\section{Introduction}

Tripterygium regelii is wide spread in North-east Asia and is used as an herbal medicine to treat swelling, chills and inflammation (Brinker et al. 2007). Quinonemethide triterpenoids isolated from T. regelii such as celastrol, iguestein, pristimerin, and tingenone

Jin-Hyo Kim $(\bowtie)$

E-mail:jhkim75@gnu.ac.kr

${ }^{1}$ National Institute of Crop Science, Rural Development Administration, Wanju 55365, Republic of Korea

${ }^{2}$ Division of Applied Life Science (BK21 plus), Institute of Agriculture and Life Science, Gyeongsang National University, Jinju 52727, Republic of Korea

This is an Open Access article distributed under the terms of the Creative Commons Attribution Non-Commercial License (http://creativecommons. org/licenses/by-nc/3.0/) which permits unrestricted non-commercial use, distribution, and reproduction in any medium, provided the original work is properly cited. are reported to possess several biological activities such as anticancer, anti-inflammatory, antimalarial, antioxidant, antiviral, and insecticidal activities (Luo et al. 2005; Brinker et al. 2007; Gao et al. 2007; Su et al. 2009; Ryu et al. 2010) as well as antifungal activity (Dos Santos et al. 2010). Furthermore, these triterpenoids induced an increase in intracellular reactive oxygen species (ROS) and mitochondrial dysfunction (Byun et al. 2009), and the quinonemethide moiety with electrochemical potential is regarded as a key component of the triterpenoid (Ryu et al. 2010). Despite the many biological activities of quinonemethide triterpenoid, the structure-based antifungal activity with quinomethide triterpenoid derivatives and the antifungal mechanism has not been well studied.

Over 20 species of Candida cause candidiasis in humans such as thrush, vaginal yeast infection, and invasive candidiasis. Another pathogenic yeast, Cryptococcus neoformans, is an ubiquitous human pathogen and causes life-threatening meningoencephalitis (Heitman and Lin 2006). Approximately one million cases of cryptococcosis in immunocompromised patients are reported globally each year, with over $60 \%$ mortality. To treat the fungal disease, the therapeutics used currently are amphotericin B, flucytosine, and fluconazole, which were developed from antifungal screening on natural extracts and structure-based semisynthesis from a key module (Estevinho et al. 2011; Pasqua et al. 2011; Kim et al. 2014). Even though therapeutic drugs were successfully developed, new antifungal development research is ongoing due to adverse effects and the increasing resistance of strains to the therapeutics. Thus, development studies for new structure modules or mode of action (MOA) candidates is highlighted currently. Herein, we studied the antifungal activity of the quinonemethide from Celastraceae against several pathogenic fungi such as Candida albicans (SC5314), Candida tropicalis (KCTC7212), Candida parapsilosis (KCTC7214), Candida glabrata (KCTC7219), and Cryptococcus neoformans (H99) as well as the antifungal mechanism based on reactive oxygen species (ROS) dependent gene expression on $C$. neoformans. 


\section{Materials and Methods}

\section{Preparation of quinonemethide}

Four quinonemethide triterpenoids (celastrol 1, iguestein 3, pristimerin 4 and tingenone 5) were isolated from Tripterygium regelii and dihydrocelastrol 2 was prepared from isolated celastrol by the reported method (Seo et al. 2011). Briefly, the stem bark of Tripterygium regelii was collected at Jiri Mountain (Korea). The stem root $(5 \mathrm{~kg})$ of T.regelii was air-dried, chopped and extracted three times with $95 \% \mathrm{MeOH}(3 \times 10 \mathrm{~L})$ for 7 days at room temperature. The combined extract was concentrated, and the dark residue $(453 \mathrm{~g})$ was partitioned between water and chloroform $(1 \mathrm{~L}: 1 \mathrm{~L})$. The organic layer was concentrated to give a dark brown residue $(310 \mathrm{~g})$ and the $\mathrm{CHCl}_{3}$ extract was subjected to column chromatography using silica gel with hexane-acetone gradient and hexane-EtOAc gradient. Fifteen pooled fractions (Fr.1-Fr.30) were obtained after combining fractions with similar TLC profiles from this initial column chromatography. The column was eluted with solvents of increasing polarity $\left(\mathrm{CHCl}_{3^{-}}\right.$ acetone) to give 30 fractions. Fraction 5 (14.3 g) was chromatographed on a silica gel column with hexane-acetone to give compounds 1 (celastrol, $280 \mathrm{mg}$ ) $\left[\mathrm{R}_{f} 0.53\right.$ (hexane/acetone=4/1)], and compound 3 (iguesterin, $100 \mathrm{mg}$ ) $\left[\mathrm{R}_{f} 0.51\right.$ (hexane/EtOAc= $2 / 1)$ ], respectively. Fraction 10 (21.6 g) was chromatographed on a silica gel column and eluted with hexane-EtOAc to give compound 4 (pristimerine, $120 \mathrm{mg}$ ) $\left[\mathrm{R}_{f} 0.27\right.$ (hexane/Acetone $=3 /$ 1)], and compound 5 (tingenone, $78 \mathrm{mg}$ ) $\left[\mathrm{R}_{f} 0.27\right.$ (hexane/ Acetone $=2 / 1)$ ]. Dihydrocelastrol 2 was prepared through the hydrogenation of celastrol with $10 \% \mathrm{Pd} / \mathrm{C}$ in ethanol. The detailed preparation information and identification data are available in supporting information.

\section{Measuring of minimal inhibitory concentration}

To determine the MIC of the compounds, the microdilution method was used according to the recommendations of the National Committee for Clinical Laboratory Standards (reference method for broth dilution antifungal susceptibility testing of yeasts; approved standard NCCLS Document M27-A2). Briefly, cells were grown in YPD medium at $30{ }^{\circ} \mathrm{C}$ overnight and were diluted with RPMI-1640 medium. The cell suspension containing $2.5 \times 10^{3}$ cells was added to the wells of a flat-bottom 96 well plate. Two-fold serial dilutions of compounds were added to the wells, and the plates were incubated at $34{ }^{\circ} \mathrm{C}$ for $72 \mathrm{~h}$. The MIC was defined as the lowest concentration that did not allow the detection of any fungal growth and was determined visually by comparing with the growth in the drug-free well (Kim et al. 2014).

\section{Real-time PCR analysis}

The overnight cultures of the $C$. neoformans (H99) were diluted to $1 \times 10^{8}$ cells in $5 \mathrm{~mL}$ of RPMI-1640 medium (pH7.2) containing $5 \mu \mathrm{g} / \mathrm{mL}$ of quinonemethide and incubated at $30^{\circ} \mathrm{C}$ for $6 \mathrm{~h}$. Total RNA was extracted using QIAzol lysis agent (QIAGEN, German),
(A)
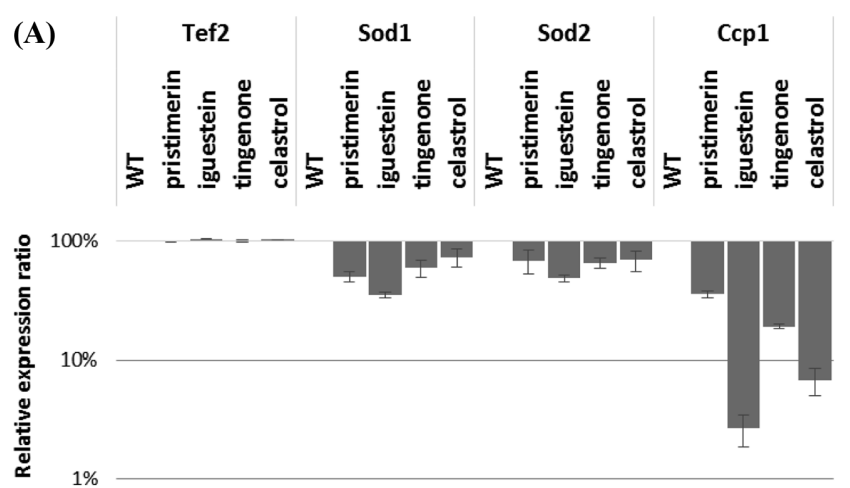

(B)

\begin{tabular}{|ll}
\hline Tef2_F & CCTTCCTTGCCCTCTTCTCAT \\
Tef2_R & AGCGACGACAGGGACAATG \\
Sod1_F & GCCGCTCAGCTCGACTTTT \\
Sod1_R & GATGGAGTGAGGGCCGTAGA \\
Sod2_F & TCGAGCTACTCTCCGCACTTC \\
Sod2_R & GGGTGTGCTTGGCCCTAAT \\
Ccp1_F & TCAGGCGGCCCTACCA \\
Ccp1_R & GAGCGGCGTATCCGTCAA \\
\hline
\end{tabular}

Fig. 1 ROS dependent gene (tef2, $\operatorname{sod} 1, \operatorname{sod} 2$ and $\operatorname{ccp} 1)$ expression ratio after treatment of natural quinonemethide (A) and list of primers used for quantitative RT-PCR analysis (B)

and cDNA was synthesized with the RevertAid ${ }^{\mathrm{TM}}$ First Strand cDNA synthesis Kit (Thermo Fisher Scientific, Canada) following the manufacturer's instructions. The relative gene expression experiments were performed by quantitative real-time PCR using a 7500 system of Applied Biosystems (Carlsbad, CA, USA) based on the $2^{-\Delta \Delta C}$ method. The primers for real-time PCR were designed using Primer Express software 3.0 (Applied Biosystems) (Fig. 1). The transcript levels of superoxide dismutase $1(\operatorname{sod} 1)$, superoxide dismutase $2(\operatorname{sod} 2)$, and cyctochrome $c$ peroxidase (ccpl) were monitored, and translation elongation factor 2 (tef2) was used as the internal control.

\section{Construction of strain}

The sequence of the ccpl (CNAG_01138) gene was obtained from the $C$. neoformans var. grubii serotype A genome database (http:/www.broadinstitute.org/annotation/genome/cryptococcus neoformans). The strain expressing the Ccpl-FLAG fusion protein was constructed using the primers listed in supporting information. To construct the strain, the $c c p 1$ gene was amplified with primers Ccp1(FLAG)_F and Ccp1(FLAG)_R using wildtype genomic DNA as the template. The amplified $2.6 \mathrm{~kb}$ DNA fragment was digested by Hind III and BamH I and then was ligated with the plasmid pWH181 containing the $3 \times$ FLAG epitope tag (DYKDDDDK), the GAL7 terminator and the nourseothricin resistance (NAT) gene. The ligated plasmid, named pWH204, was linearized by $S a l$ I and introduced into the wild-type $C$. neoformans by biolistic transformation (Yu et al. 2004). Positive transformants including the recombinant gene at the ccpl locus were confirmed by PCR using Ccp1(FLAG)_F and NATterm2F 
and western blot analysis.

\section{Western blot analysis}

The strains expressing Ccp1-FLAG fusion protein were cultured in yeast extract-Bacto peptone medium containing $2.0 \%$ glucose (YPD) in $30{ }^{\circ} \mathrm{C}$ for $16 \mathrm{~h}$, and transferred into RPMI-1640 medium (pH 7.2) containing $5 \mu \mathrm{g} / \mathrm{mL}$ quinone-methide. The cells were incubated at $30{ }^{\circ} \mathrm{C}$ for $16 \mathrm{~h}$ prior to harvesting, and the pellets were resuspended in protein extraction buffer including $1 \%$ Triton X-100, $50 \mathrm{mM}$ HEPES KOH at $\mathrm{pH}$ 7.5, 1 mM EDTA, 140 $\mathrm{mM} \mathrm{NaCl}, 0.1 \%$ Na-deoxycholate, $1 \mathrm{mM}$ PMSF and a protease inhibitor cocktail (Sigma-Aldrich Co. MO, USA) (Do et al. 2015). The cells were disrupted with acid-washed glass-beads $(0.4 \mathrm{~mm}$; Sigma-Aldrich Co. MO, USA) using a bead-beater (BioSpec, Bartlesville, OK, USA). Total protein concentration was determined with the Bradford assay (Bradford 1976). Western blot analysis was performed using an anti-DDDDK polyclonal rabbit antibody (Abcam, UK) as the primary antibody and a goat anti-rabbit IgG horseradish peroxidase conjugate (Santa Cruz Biotechnology, TX, USA) as the secondary antibody, followed by visualization using chemiluminescence (Do et al. 2015). The band intensities were measured with ImageJ 1.50i (Windows version of NIH Image, http://imagej.nih.gov/) (Gassmann et al. 2009).

\section{Results and Discussion}

First, all the triterpenoids except dihydrocelastrol showed strong inhibitory potentials at sub-micromolar concentrations (MIC $0.269-0.555 \mu \mathrm{M})$ on $C$. glabrata and at micromolar concentrations (MIC $0.552-8.877 \mu \mathrm{M}$ ) on $C$. albicans, $C$. tropicalis, and $C$. neoformans (Table 1). Their inhibition activities were comparable to fluconazole (MIC $0.816-6.532 \mu \mathrm{M}$ ) as the positive control, and C. glabrata was more susceptible than other candida fungi to the triterpene. However, no clue to the key structure module for the biological activity could be found from the constitutional derivation of the triterpene.

To understand the antifungal activity of the quinonemethide, the ROS dependent gene expressions in $C$. neoformans were measured owing to their known antioxidative activity (Allison et al. 2001, Wang et al. 2014). Because terpenoids are known to induce an increase in intracellular ROS, we selected genes encoding antioxidant proteins, sodl and sod2, for the superoxide dismutases that convert superoxide radical to hydrogen peroxide, and ccpl,

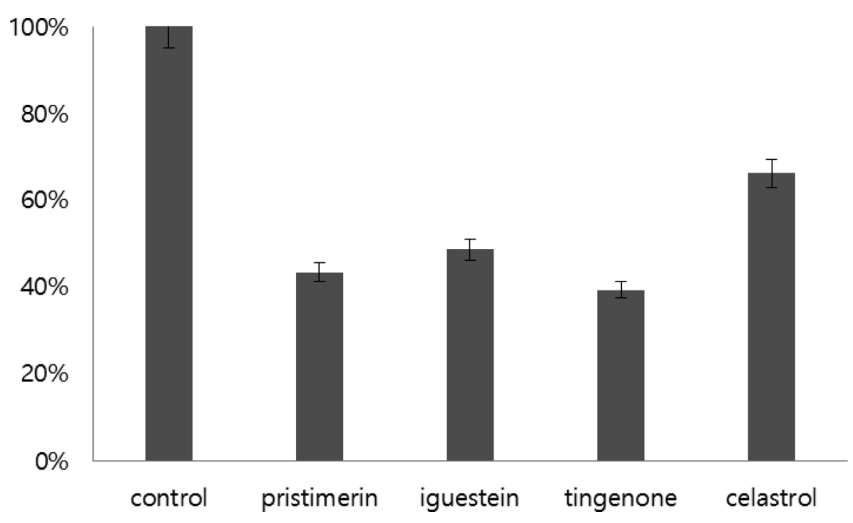

Fig. 2 Relative quantification of cyctochrome $c$ peroxidase expression by Western blot

for the cytochrome $c$ peroxidase that detoxifies hydrogen peroxide (Cox et al. 2003; Narasipura et al. 2003; Giles et al. 2005; Narasipura et al. 2005). In the gene expression experiment, the tendency of the anti-oxidant gene expression decreased when the cells were exposed to quinonemethide. Especially, the ccpl expression significantly decreased 3-38 folds, indicating that the antifungal quinonemethide triterpenoids inhibits protection against oxidative stress in C. neoformans (Fig. 1). Considering the role of ccpl, exerting resistance against oxidative stress and functioning as a sensor of antioxidants, the strong inhibition of $c c p 1$ results in the inhibition of growth by the quinonemethide (Giles et al. 2005; Martins et al. 2013). We also constructed a strain expressing the Ccp1-FLAG fusion protein and evaluated the protein levels in the cells treated with each compound $(\mathbf{1}, \mathbf{3}, \mathbf{4}, \mathbf{5})$. The results in Fig. 2 showed that treatment of the compound reduced the protein levels by over $40 \%$ and were in agreement with our quantitative real-time PCR data, although no exact correlation was observed between transcript and protein levels.

In summary, the quinonemethide triterpenoids celastrol, dihydrocelastrol, iguestein, pristimerin, and tingenone showed strong antifungal activity against human pathogenic fungi, and C. glabrata was more susceptible to the quinonemethide than the other tested fungi. After treatment with quinonemethide, cyctochrome $c$ peroxidase expression was significantly reduced, resulting in the accumulation of hydrogen peroxide in the fungi. Thus, this cyctochrome $c$ peroxidase downregulation is an important MOA for anti-fungal activity and could be used for screening among antioxidants to find valid anti-fungal agents.

Table 1 Minimal inhibitory concentration $(\mathrm{mM})$ of the quinonemethide triterpenoids on pathogenic fungi

\begin{tabular}{lccccc}
\hline & Fluconazole & Celastrol & Dihydrocelastrol & Iguestein & Pristimerin \\
\hline C. albicans & 0.816 & 4.439 & 4.419 & 1.236 & 4.076 \\
C. tropicalis & $>418$ & 8.877 & 17.67 & 2.472 & 4.305 \\
C. parapsilosis & 3.266 & 17.754 & 17.67 & 4.944 & 17.21 \\
C. glabrata & 1.633 & 0.555 & 0.276 & 0.309 & 1 \\
C. neoformans & 6.532 & 4.439 & 0.552 & 1.236 & 0.269 \\
\hline
\end{tabular}


Acknowledgments This study was carried out with the support of the "Cooperative Research Program for Agriculture Science \& Technology Development (Project No.: PJ00925701)” RDA, Republic of Korea.

\section{References}

Allison AC, Cacabelos R, Lombardi VR, Alvarez XA, Vigo C (2001) Celastrol, a potent antioxidant and anti-inflammatory drug, as a possible treatment for Alzheimer's disease. Prog Neuropsychopharmacol Biol Psychiatry 25: 1341-1357

Bradford MM (1976) A rapid and sensitive method for the quantitation of microgram quantities of protein utilizing the principle of protein-dye binding. Anal Biochem 72: 248-254

Brinker AM, Ma J, Lipsky PE, Raskin I (2007) Medicinal chemistry and pharmacology of genus Tripterygium (Celastraceae). Phytochem 68: 732-766

Byun JY, Kim MJ, Eum DY, Yoon CH, Seo WD, Park KH, Hyun JW, Lee YS, Yoon MY, Lee SJ (2009) Reactive oxygen species-dependent activation of Bax and poly (ADP-ribose) polymerase-1 is required for mitochondrial cell death induced by triterpenoid pristimerin in human cervical cancer cells. Mol Pharmacol 76: 734-744

Cox GM, Harrison TS, McDade HC, Taborda CP, Heinrich G, Casadevall A, Perfect JR (2003) Superoxide dismutase influences the virulence of Cryptococcus neoformans by affecting growth within macrophages. Infect Immun 71: 173-180

Do E, Hu G, Caza M, Oliveira D, Kronstad JW, Jung WH (2015) Leu1 plays a role in iron metabolism and is required for virulence in Cryptococcus neoformans. Fungal Genet Biol 75: 11-19

Dos Santos VA, Dos Santos DP, Castro-Gamboa I, Zanoni MV, Furlan M (2010) Evaluation of antioxidant capacity and synergistic associations of quinonemethide triterpenes and phenolic substances from Maytenus ilicifolia (Celastraceae). Molecules 15: 6956-6973

Estevinho ML, Afonso SE, Feas X (2011) Antifungal effect of lavender honey against Candida albicans, Candida krusei and Cryptococcus neoformans. J Food Sci Technol-Mysore 48: 640-643

Gao JM, Wu WJ, Zhang JW, Konishi Y (2007) The dihydro-beta-agarofuran sesquiterpenoids. Nat Prod Rep 24: 1153-1189

Gassmann M, Grenacher B, Rohde B, Vogel J (2009) Quantifying Western blots: pitfalls of densitometry. Electrophoresis 30: 1845-1855

Giles SS, Perfect JR, Cox GM (2005) Cytochrome c peroxidase contributes to the antioxidant defense of Cryptococcus neoformans. Fungal Genet Biol 42: $20-29$

Heitman J, Lin XR (2006) The biology of the Cryptococcus neoformans species complex. Ann Rev Microbiol 60: 69-105

Kim JH, Lee HO, Cho YJ, Kim J, Chun J, Choi J, Lee Y, Jung WH (2014) A vanillin derivative causes mitochondrial dysfunction and triggers oxidative stress in Cryptococcus neoformans. PLoS One 9: e89122

Luo DQ, Wang H, Tian X, Shao HJ, Liu JK (2005) Antifungal properties of pristimerin and celastrol isolated from Celastrus hypoleucus. Pest Manag Sci 61: 85-90

Martins D, Kathiresan M, English AM (2013) Cytochrome c peroxidase is a mitochondrial heme-based $\mathrm{H} 2 \mathrm{O} 2$ sensor that modulates antioxidant defense. Free Radic Biol Med 65: 541-551

Narasipura SD, Ault JG, Behr MJ, Chaturvedi V, Chaturvedi S (2003) Characterization of $\mathrm{Cu}, \mathrm{Zn}$ superoxide dismutase (SOD1) gene knockout mutant of Cryptococcus neoformans var. gattii: role in biology and virulence. Mol Microbiol 47: 1681-1694

Narasipura SD, Chaturvedi V, Chaturvedi S (2005) Characterization of Cryptococcus neoformans variety gattii SOD2 reveals distinct roles of the two superoxide dismutases in fungal biology and virulence. Mol Microbiol 55: 1782-1800

Pasqua G, Tocci N, Simonetti G, D'Auria FD, Panella S, Palamara AT, Valletta A, Pasqua G (2011) Root cultures of Hypericum perforatum subsp. angustifolium elicited with chitosan and production of xanthone-rich extracts with antifungal activity. Appl Microbiol Biotech 91: 977-987

Ryu YB, Park SJ, Kim YM, Lee JY, Seo WD, Chang JS, Park KH, Rho MC, Lee WS (2010) SARS-CoV 3CLpro inhibitory effects of quinonemethide triterpenes from Tripterygium regelii. Bioorg Med Chem Lett 20: $1873-1876$

Seo HR, Seo WD, Pyun BJ, Lee BW, Jin YB, Park KH, Seo EK, Lee YJ, Lee YS (2011) Radiosensitization by celastrol is mediated by modification of antioxidant thiol molecules. Chem Biol Interact 193: 34-42

Su XH, Zhang ML, Zhan WH, Huo CH, Shi QW, Gu YC, Kiyota H (2009) Chemical and pharmacological studies of the plants from genus Celastrus. Chem Biodivers 6: 146-161

Wang C, Shi C, Yang X, Yang M, Sun H, Wang C (2014) Celastrol suppresses obesity process via increasing antioxidant capacity and improving lipid metabolism. Eur J Pharmacol 744: 52-58

Yu JH, Hamari Z, Han KH, Seo JA, Reyes-Dominquez Y, Scazzocchio C (2004) Double-joint PCR: a PCR-based molecular tool for gene manipulations in filamentous fungi. Fungal Genet Biol 41: 973-981 